\title{
Impact of knee osteoarthritis on surgical outcomes of lumbar spinal canal stenosis
}

\author{
Masahiro Ozaki, MD, 1,5 Nobuyuki Fujita, MD,, 2,3,5 Azusa Miyamoto,, ${ }^{1,5}$ Satoshi Suzuki, MD, 2,5 \\ Osahiko Tsuji, MD, ${ }^{2,5}$ Narihito Nagoshi, MD, ${ }^{2,5}$ Eijiro Okada, MD, ${ }^{2,5}$ Mitsuru Yagi, MD, , 2, \\ Takashi Tsuji, MD,, Masaya Nakamura, MD, , ${ }^{2,5}$ Morio Matsumoto, MD, ${ }^{2,5}$ Hitoshi Kono, MD, ,,5 and \\ Kota Watanabe, MD2,5
}

'Keiyu Orthopedic Hospital, Gunma; ²Department of Orthopaedic Surgery, Keio University School of Medicine, Tokyo; 3Department of Orthopaedic Surgery, Fujita Health University, Aichi; ${ }^{4}$ Department of Orthopaedic Surgery, Tokyo Medical Center, Tokyo; and ${ }^{5}$ Keio Spine Research Group (KSRG), Tokyo, Japan

OBJECTIVE Lumbar spinal canal stenosis (LSS) and knee osteoarthritis (KOA), both of which are age-related degen-
erative diseases, are independently correlated with increased pain and dysfunction of the lower extremities. However,
there have been few studies that investigated whether LSS patients with KOA exhibit poor clinical recovery following
lumbar spinal surgery. The aim of this study was to elucidate the surgical outcomes of lumbar spinal surgery for LSS
patients with KOA using multiple health-related quality of life (HRQOL) parameters. METHODS A total of 865 consecutive patients who underwent posterior lumbar spinal surgery for LSS were retrospectively reviewed. Baseline characteristics, radiographic parameters, perioperative factors, and multiple HRQOL parameters were analyzed preoperatively and at 1-year follow-up. HRQOL items included the Zurich Claudication Questionnaire, Oswestry Disability Index, Medical Outcomes Study 36-Item Short-Form Health Survey (SF-36), and Japanese Orthopaedic Association Back Pain Evaluation Questionnaire (JOABPEQ). The effectiveness of surgical treatment was assessed using the JOABPEQ. The treatment was regarded as effective when it resulted in an increase in postoperative JOABPEQ score by $\geq 20$ points compared with preoperative score or achievement of a postoperative score of $\geq 90$ points in those with a preoperative score of $<90$ points.

RESULTS A total of 32 LSS patients with KOA were identified, and 128 age- and sex-matched LSS patients without KOA were selected as controls. In both groups, all HRQOL parameters markedly improved at the 1-year follow-up. On the SF-36, the postoperative mean score for the role physical domain was significantly lower in the KOA group than in the control group $(p=0.034)$. The treatment was significantly less "effective" in the social life domain of JOABPEQ in the KOA group than in the control group $(p<0.001)$.

CONCLUSIONS The surgical outcomes of LSS patients with KOA are favorable, although poorer than those of LSS patients without KOA, particularly in terms of social life and activities. These results indicate that LSS patients with KOA experience difficulty in routine work or ordinary activities due to knee pain or restricted knee ROM even after lumbar spinal surgery. Hence, preoperative KOA status warrants consideration when planning lumbar spinal surgery and estimating surgical outcomes of LSS.

https://thejns.org/doi/abs/10.3171/2019.10.SPINE19886

KEYWORDS lumbar spinal canal stenosis; knee osteoarthritis; surgical outcome; health-related quality of life; intervertebral disc degeneration; facet joint osteoarthritis; degenerative

ABBREVIATIONS DDD = degenerative disc disease; $\mathrm{DM}=$ diabetes mellitus; $\mathrm{HL}$ = hyperlipidemia; $\mathrm{HRQOL}=$ health-related quality of life; $\mathrm{HTN}=$ hypertension; JOABPEQ = Japanese Orthopaedic Association Back Pain Evaluation Questionnaire; KOA = knee osteoarthritis; LL = lumbar lordosis; LSS = lumbar spinal canal stenosis; ODI = Oswestry Disability Index; PI = pelvic incidence; PT = pelvic tilt; ROM = range of motion; SF-36 = Medical Outcomes Study 36-Item Short-Form Health Survey; SS = sacral slope; SVA = sagittal vertical axis; TK = thoracic kyphosis; TKR = total knee replacement; VAS = visual analog scale; ZCQ = Zurich Claudication Questionnaire. SUBMITTED July 28, 2019. ACCEPTED October 22, 2019.

INCLUDE WHEN CITING Published online December 27, 2019; DOI: 10.3171/2019.10.SPINE19886. 
$\mathrm{L}$ UMBAR spinal canal stenosis (LSS), a degenerative musculoskeletal disorder, manifests by the narrowing of the lumbar spinal canal, which compresses the cauda equina and nerve root. Patients with LSS often exhibit neurological symptoms of the lower extremities, including leg pain, numbness, motor deficit, sensory disturbance, and intermittent claudication. Age-related degenerative changes of the lumbar spine, including intervertebral disc degeneration, facet joint osteoarthritis, and hypertrophy of the ligamentum flavum, are the primary etiologies of LSS. In patients with LSS resistant to conservative therapy, lumbar spinal surgery commonly attains favorable outcomes. ${ }^{19,20}$

Knee osteoarthritis (KOA) is a degenerative joint condition ${ }^{3}$ that limits mobility due to knee pain and limited knee range of motion (ROM). Because LSS and KOA are age-related degenerative changes, many elderly patients develop both pathologies concurrently. ${ }^{13}$ In addition, LSS and KOA are independently correlated with increased pain and dysfunction of the lower extremities; ${ }^{16}$ therefore, LSS patients with KOA may exhibit poor clinical recovery following lumbar spinal surgery. Ho Lee et al. investigated surgical outcomes of LSS patients with or without KOA using the Oswestry Disability Index (ODI) and demonstrated that the presence of preoperative KOA was a poor prognostic factor for surgical outcomes of LSS.11 However, because they assessed surgical outcomes using a single self-reported health-related quality of life (HRQOL) questionnaire, no definitive conclusions could be drawn. Therefore, by using multiple HRQOL parameters, this study aimed to investigate how the KOA condition affects the surgical outcome of lumbar spinal surgery for LSS patients.

\section{Methods}

\section{Study Participants}

A total of 865 consecutive patients who underwent posterior lumbar spinal surgery for LSS from July 2015 to September 2017 were retrospectively reviewed. All patients were followed up for more than 1 year at Keiyu Orthopedic Hospital. For each patient, clinical data were collected using patient charts and operative records based on the institution's ethical guidelines. The subjects were notified of the study, and data of patients who declined to participate were excluded from the analysis.

Surgery was recommended for patients displaying clear symptoms of LSS, including leg pain and neurogenic claudication, and who were resistant to conservative therapy. The LSS diagnosis was validated using MRI or myelography. Figure 1 presents the flowchart of this case-control study. Cases with failed back surgery syndrome $(n=124)$, those with fusion segments $\geq 4$ in lumbar surgery $(n=11)$, those with a history of orthopedic surgery at other sites that included total knee replacement (TKR; $n=58)$, those with major postoperative complications such as spinal epidural hematoma and vertebral compression fracture $(n=12)$, and those with a medical history of hip osteoarthritis were excluded $(n=19)$. Following the initial identification of KOA based on medical history, cases with radiographic KOA of Kellgren-Lawrence grade $\geq 2(n=32)$ were included in this study. Cases who had undergone TKR within 1 year after lumbar surgery were excluded $(n=4)$. For each LSS patient with KOA, 4 age- and sex-matched controls were selected from a group of LSS patients without a history of KOA (n $=557$ ). Finally, 32 patients with KOA (KOA group) and 128 controls (control group) were enrolled. To validate this matching analysis, we divided the total of 641 patients into 80 KOA patients without TKR and 557 non-KOA patients according to only medical history, and performed the comparative analysis between the two groups.

\section{Data Collection}

Complete preoperative and 1-year follow-up data on the visual analog scale (VAS), Zurich Claudication Questionnaire (ZCQ), ODI, Medical Outcomes Study 36-Item

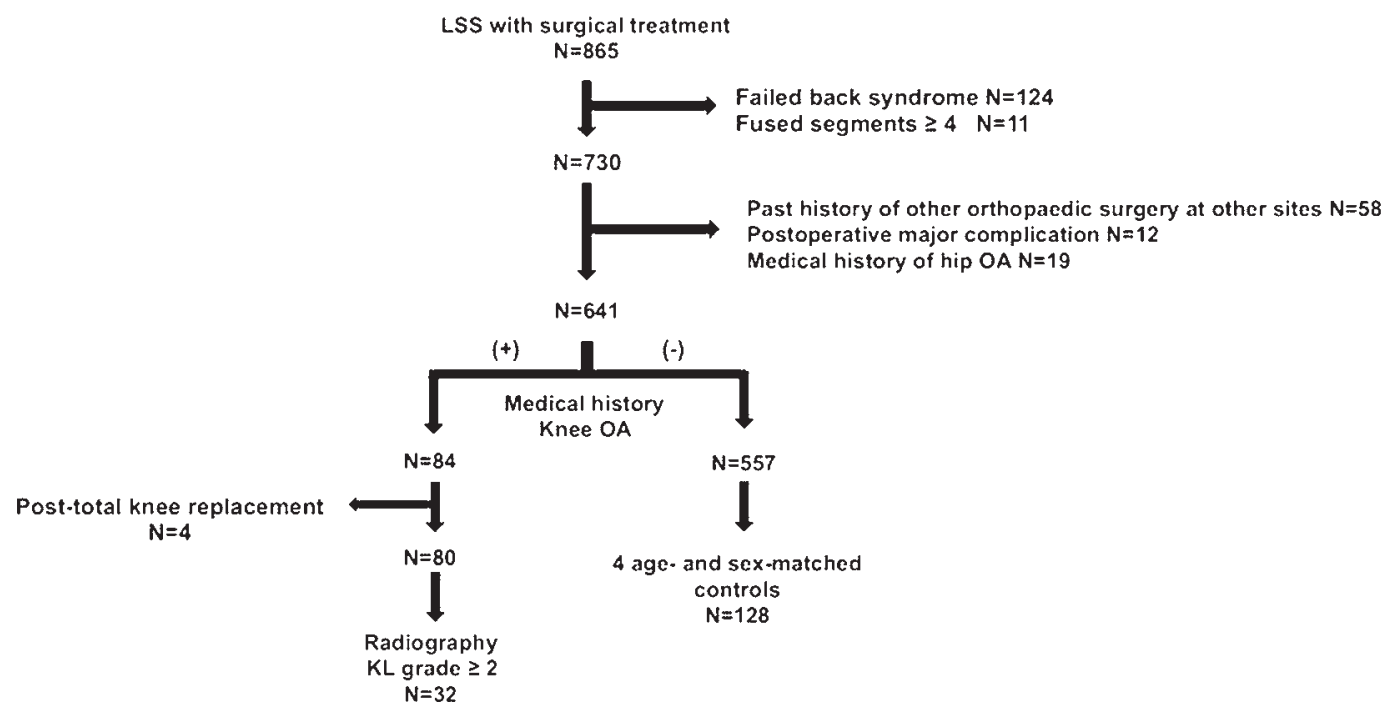

FIG. 1. Flowchart of study participant selection. $\mathrm{KL}=$ Kellgren-Lawrence; $\mathrm{OA}=$ osteoarthritis. 
Short-Form Health Survey (SF-36), and Japanese Orthopaedic Association Back Pain Evaluation Questionnaire (JOABPEQ) were available for all patients. In addition, the following data were collected for each patient: age; sex; BMI; perioperative factors; smoking habit; and medical history, including diabetes mellitus (DM), hypertension (HTN), hyperlipidemia (HL), heart disease, and cancer.

\section{Therapeutic Effect of Lumbar Surgery}

The therapeutic effect of lumbar spinal surgery was evaluated using the JOABPEQ. To ascertain the therapeutic effect of lumbar spinal surgery in patients in terms of each domain of the JOABPEQ, the following were assessed: 1) increase in postoperative score by $\geq 20$ points compared with preoperative score, or 2) postoperative score reaching $\geq 90$ points with preoperative score of $<90$ points; when either of these conditions was satisfied, the treatment was judged "effective."9 The definition of "effective" has been validated by multiple investigations of the JOABPEQ. ${ }^{6-8}$

\section{Radiographic Parameters}

The following radiographic data were recorded from standing full-length radiographs of the spine: anterior percentage slip, sagittal vertical axis (SVA), thoracic kyphosis (TK), lumbar lordosis (LL), sacral slope (SS), pelvic tilt (PT), and pelvic incidence (PI). In addition, the spinopelvic alignment was analyzed based on PI-LL, SVA, TK, LL, PI, and PT, as previously described. ${ }^{21}$ Spondylolisthesis was defined as $\geq 10 \%$ anterior slippage of the upper vertebra.

\section{MRI}

Intervertebral disc degeneration was assessed from L1-2 to L5-S1 using the sagittal images of lumbar MRI. Intervertebral disc degeneration was graded using Schneiderman's classification, ${ }^{17}$ and the degenerative disc disease (DDD) score was evaluated based on the summation of Schneiderman's score for each lumbar level, as described previously. ${ }^{2}$

\section{CT}

Facet joint osteoarthritis was assessed from L3-4 to L5-S1 using the axial images of lumbar spine CT. Facet joint osteoarthritis was graded, as described previously: grade $0=$ normal facet joint, grade $1=$ joint space narrowing, grade $2=$ sclerosis, and grade $3=$ osteophytes.$^{15}$

\section{Statistical Analysis}

Data were presented as means \pm standard deviations. Differences between the KOA and control groups were evaluated using Pearson's chi-square test, Student t-test, Mann-Whitney U-test, and Wilcoxon signed-rank test. A $\mathrm{p}$ value $<0.05$ was considered statistically significant. All statistical analyses were performed using the Statistical Package for the Social Sciences (SPSS version 21.0, IBM Corp.).

\section{Results}

\section{Characteristics of LSS Patients With KOA}

The baseline characteristics of the study cohort were
TABLE 1. Baseline characteristics

\begin{tabular}{lccc}
\hline \multicolumn{1}{c}{ Variable } & $\begin{array}{c}\text { KOA Group } \\
(\mathrm{n}=32)\end{array}$ & $\begin{array}{c}\text { Control Group } \\
(\mathrm{n}=128)\end{array}$ & $\begin{array}{c}\mathrm{p} \\
\text { Value }^{*}\end{array}$ \\
\hline Mean age $\pm \mathrm{SD}$ & $69.1 \pm 8.3$ & $68.8 \pm 8.3$ & 0.891 \\
\hline Sex & & & \\
\hline Males:females & $7: 25$ & $27: 101$ & 0.923 \\
\hline$\%$ male & 21.9 & 21.1 & \\
\hline Mean BMl $\pm \mathrm{SD}, \mathrm{kg} / \mathrm{m}^{2}$ & $25.2 \pm 3.8$ & $24.2 \pm 3.3$ & 0.135 \\
\hline Medical history, $\mathrm{n}(\%)$ & & & \\
\hline DM & $5(15.6)$ & $20(15.6)$ & 0.959 \\
\hline HTN & $10(31.3)$ & $53(41.4)$ & 0.293 \\
\hline HL & $2(6.3)$ & $6(4.7)$ & 0.717 \\
\hline Heart disease & $2(6.3)$ & $2(1.6)$ & 0.256 \\
\hline Cancer & $0(0.0)$ & $1(0.8)$ & 0.616 \\
\hline Smoking & $4(12.5)$ & $11(8.6)$ & 0.498 \\
\hline Kellgren-Lawrence grade, $\mathrm{n}(\%)$ & & & \\
\hline 2 & $22(68.8)$ & & \\
\hline 3 & $8(25.0)$ & & \\
\hline 4 & $2(6.3)$ & & \\
\hline
\end{tabular}

* Mann-Whitney U-test or chi-square test.

similar between the two groups, including mean age; sex ratio; mean BMI; prevalence of DM, HTN, HL, heart disease, and cancer; and smoking habit (Table 1). In the KOA group, the proportion of patients with KOA of KellgrenLawrence grades 2, 3, and 4 was $68.8 \%(\mathrm{n}=22), 25.0 \%$ ( $\mathrm{n}$ $=8)$, and $6.3 \%(\mathrm{n}=2)$, respectively (Table 1$)$. Regarding preoperative radiographic parameters, PT was significantly higher in the KOA group than that in the control group $\left(27.3^{\circ} \pm 8.6^{\circ}\right.$ vs $24.1^{\circ} \pm 9.2^{\circ}, \mathrm{p}=0.046$; Table 2$)$. Other sagittal radiographic parameters exhibited no significant difference between the two groups. Regarding perioperative factors, no significant differences were noted in the number of decompression levels, percentage of fusion surgery, operative durations, and amount of blood loss between the two groups (Table 3). In addition, the DDD score was

TABLE 2. Comparison of preoperative radiographic parameters between the KOA and control groups

\begin{tabular}{lccc}
\hline $\begin{array}{c}\text { Preop Radiographic } \\
\text { Parameter }\end{array}$ & $\begin{array}{c}\text { KOA Group } \\
(n=32)\end{array}$ & $\begin{array}{c}\text { Control Group } \\
(n=128)\end{array}$ & $\begin{array}{c}p \\
\text { Value }\end{array}$ \\
\hline Forward slip $(>10 \%)$ & $16(50.0 \%)$ & $71(55.5 \%)$ & 0.609 \\
\hline SVA $(\mathrm{mm})$ & $58.3 \pm 50.1$ & $49.6 \pm 50.1$ & 0.368 \\
\hline $\mathrm{TK}\left({ }^{\circ}\right)$ & $27.6 \pm 13.0$ & $24.7 \pm 10.6$ & 0.218 \\
\hline $\mathrm{LL}\left({ }^{\circ}\right)$ & $-34.7 \pm 16.1$ & $-36.4 \pm 17.0$ & 0.615 \\
\hline $\mathrm{PT}\left({ }^{\circ}\right)$ & $27.3 \pm 8.6$ & $24.1 \pm 9.2$ & 0.046 \\
\hline $\mathrm{SS}\left({ }^{\circ}\right)$ & $26.1 \pm 9.4$ & $28.0 \pm 10.9$ & 0.370 \\
\hline $\mathrm{PI}\left({ }^{\circ}\right)$ & $53.4 \pm 11.4$ & $52.0 \pm 12.7$ & 0.581 \\
\hline $\mathrm{PI}-\mathrm{LL}\left({ }^{\circ}\right)$ & $18.4 \pm 15.0$ & $15.2 \pm 15.1$ & 0.244 \\
\hline
\end{tabular}

Data are given as mean \pm standard deviation unless otherwise noted. Boldface type indicates statistical significance.

* Mann-Whitney U-test, t-test, or chi-square test. 
TABLE 3. Comparison of perioperative factors between the KOA and control groups

\begin{tabular}{lccc}
\hline \multicolumn{1}{c}{ Periop Factor } & $\begin{array}{c}\text { KOA Group } \\
(\mathrm{n}=32)\end{array}$ & $\begin{array}{c}\text { Control Group } \\
(\mathrm{n}=128)\end{array}$ & $\begin{array}{c}\mathrm{p} \\
\text { Value }^{*}\end{array}$ \\
\hline $\begin{array}{l}\text { Mean no. of decompression } \\
\text { levels } \pm \text { SD }\end{array}$ & $1.6 \pm 0.6$ & $1.5 \pm 0.6$ & 0.882 \\
\hline $\begin{array}{l}\text { No. w/ fusion (\%) } \\
\begin{array}{l}\text { Mean operative duration } \pm \\
\text { SD, min }\end{array}\end{array}$ & $17(53.1 \%)$ & $84(65.6 \%)$ & 0.189 \\
\hline Mean blood loss \pm SD, ml & $43.1 \pm 59.4$ & $77.8 \pm 40.9$ & 0.539 \\
\hline
\end{tabular}

${ }^{*}$ Mann-Whitney U-test or chi-square test.

significantly higher in the KOA group than in the control group $(12.7 \pm 2.2$ vs $9.7 \pm 3.3$, p $<0.001$; Supplementary Table 1). Facet joint osteoarthritis was also significantly more progressive in the KOA group than in the control group at the L3-4, L4-5, and L5-S1 levels (Supplementary Table 1).

\section{Surgical Outcomes of LSS Patients With KOA Using Multiple HRQOL Parameters}

Table 4 presents the pre- and postoperative parameters of HRQOL variables in both groups. All postoperative HRQOL parameters at 1-year follow-up were significantly improved compared with preoperative parameters in the two groups (Table 4). Pre- and postoperative ODI scores were similar between the two groups. While there was no significant difference in all preoperative VAS scores, postoperative VAS scores for buttock and lower limbs were significantly higher in the KOA group than those in the control group ( $3.8 \pm 3.3$ vs $2.4 \pm 2.8, \mathrm{p}=0.007)$. Regarding the symptom severity of the ZCQ, the preoperative mean score was significantly higher in the KOA group than in the control group $(3.6 \pm 0.5$ vs $3.3 \pm 0.7, p=0.025)$. However, the postoperative score exhibited no significant difference $(2.6 \pm 0.9$ vs $2.3 \pm 0.8, p=0.113$; Table 4$)$. The postoperative score of the satisfaction domain on the ZCQ was worse in the KOA group than in the control group, although the difference was not significant. Assessment of preoperative SF-36 scores revealed that the bodily pain score was significantly lower in the KOA group than that in the control group $(49.0 \pm 17.5$ vs $58.4 \pm 22.9, \mathrm{p}=0.038$; Table 4). In addition, postoperative SF-36 scores for physical functioning $(59.7 \pm 25.7$ vs $69.9 \pm 23.9, \mathrm{p}=0.035)$, role physical $(61.1 \pm 28.0$ vs $72.7 \pm 24.1, \mathrm{p}=0.034)$, and vitality $(49.0 \pm 20.5$ vs $56.9 \pm 16.3, \mathrm{p}=0.048)$ were significantly lower in the KOA group than in the control group. The frequency of "effective" in the pain disorder domain $(63.3 \%$ vs $80.6 \%, \mathrm{p}=0.048)$ and social life domain $(22.6 \%$ vs $62.2 \%, \mathrm{p}<0.001)$ of the JOABPEQ was significantly lower in the KOA group than in the control group (Table 5). Finally, to validate the results of this matching analysis, we compared the baseline characteristics and the HRQOL parameters between $80 \mathrm{KOA}$ patients without TKR and

TABLE 4. Comparison of pre- and postoperative variables of HRQOL between the KOA and control groups

\begin{tabular}{|c|c|c|c|c|c|c|c|c|}
\hline \multirow[b]{2}{*}{ Variable } & \multicolumn{3}{|c|}{ Preop } & \multicolumn{3}{|c|}{ Postop } & \multicolumn{2}{|c|}{ Preop vs Postop† } \\
\hline & $\begin{array}{l}\text { KOA } \\
\text { Group }\end{array}$ & $\begin{array}{l}\text { Control } \\
\text { Group }\end{array}$ & $p$ Value* & $\begin{array}{l}\text { KOA } \\
\text { Group }\end{array}$ & $\begin{array}{l}\text { Control } \\
\text { Group }\end{array}$ & $p$ Value* & $\begin{array}{l}\text { KOA } \\
\text { Group }\end{array}$ & $\begin{array}{l}\text { Control } \\
\text { Group }\end{array}$ \\
\hline \multicolumn{9}{|l|}{ VAS domain } \\
\hline Low-back pain & $5.6 \pm 2.9$ & $5.5 \pm 2.7$ & 0.832 & $3.5 \pm 3.1$ & $2.4 \pm 2.4$ & 0.058 & $<0.001$ & $<0.001$ \\
\hline Pain in buttocks \& lower limbs & $7.1 \pm 2.6$ & $6.4 \pm 2.7$ & 0.146 & $3.8 \pm 3.3$ & $2.4 \pm 2.8$ & 0.007 & $<0.001$ & $<0.001$ \\
\hline Numbness in buttocks \& lower limbs & $6.5 \pm 3.2$ & $6.4 \pm 2.9$ & 0.564 & $2.6 \pm 3.6$ & $2.5 \pm 3.0$ & 0.489 & $<0.001$ & $<0.001$ \\
\hline \multicolumn{9}{|l|}{ ZCQ domain } \\
\hline Symptom severity & $3.6 \pm 0.5$ & $3.3 \pm 0.7$ & 0.025 & $2.6 \pm 0.9$ & $2.3 \pm 0.8$ & 0.113 & $<0.001$ & $<0.001$ \\
\hline Physical functioning & $2.7 \pm 0.5$ & $2.6 \pm 0.6$ & 0.595 & $1.8 \pm 0.6$ & $1.7 \pm 0.6$ & 0.167 & $<0.001$ & $<0.001$ \\
\hline Satisfaction & & & & $2.0 \pm 0.7$ & $1.9 \pm 0.7$ & 0.158 & & \\
\hline ODI & $44.7 \pm 12.3$ & $40.2 \pm 15.3$ & 0.122 & $22.8 \pm 14.2$ & $19.3 \pm 14.1$ & 0.132 & $<0.001$ & $<0.001$ \\
\hline \multicolumn{9}{|l|}{ SF-36 domain } \\
\hline Physical functioning & $38.8 \pm 16.7$ & $41.1 \pm 19.6$ & 0.649 & $59.7 \pm 25.7$ & $69.9 \pm 23.9$ & 0.035 & $<0.001$ & $<0.001$ \\
\hline Role physical & $37.2 \pm 21.4$ & $44.5 \pm 26.4$ & 0.095 & $61.1 \pm 28.0$ & $72.7 \pm 24.1$ & 0.034 & $<0.001$ & $<0.001$ \\
\hline Bodily pain & $49.0 \pm 17.5$ & $58.4 \pm 22.9$ & 0.038 & $79.3 \pm 21.3$ & $85.1 \pm 16.7$ & 0.206 & $<0.001$ & $<0.001$ \\
\hline General health & $36.2 \pm 16.8$ & $38.6 \pm 15.2$ & 0.426 & $54.3 \pm 23.2$ & $59.8 \pm 16.6$ & 0.212 & $<0.001$ & $<0.001$ \\
\hline Vitality & $39.4 \pm 18.4$ & $40.2 \pm 18.5$ & 0.940 & $49.0 \pm 20.5$ & $56.9 \pm 16.3$ & 0.048 & 0.002 & $<0.001$ \\
\hline Social functioning & $58.7 \pm 31.5$ & $63.0 \pm 26.0$ & 0.602 & $74.3 \pm 27.5$ & $81.3 \pm 24.9$ & 0.143 & 0.004 & $<0.001$ \\
\hline Role emotional & $48.3 \pm 28.0$ & $50.9 \pm 29.5$ & 0.451 & $77.4 \pm 51.2$ & $76.2 \pm 25.8$ & 0.627 & 0.003 & $<0.001$ \\
\hline Mental health & $52.8 \pm 21.0$ & $52.5 \pm 21.0$ & 0.763 & $65.2 \pm 24.5$ & $70.5 \pm 18.8$ & 0.406 & $<0.001$ & $<0.001$ \\
\hline
\end{tabular}

VAS scores: $0=$ comfortable condition without any pain at all, $10=$ the most intense pain (numbness) imaginable. Boldface type indicates statistical significance.

* Mann-Whitney U-test or t-test.

$\dagger \mathrm{t}$-test or Wilcoxon signed-rank test. 
TABLE 5. Comparison of effectiveness of surgical treatment on the JOABPEQ between the KOA and control groups

\begin{tabular}{|c|c|c|c|c|c|c|c|}
\hline \multirow[b]{2}{*}{ JOABPEQ Domain } & \multicolumn{3}{|c|}{ KOA Group $(n=32)$} & \multicolumn{3}{|c|}{ Control Group $(\mathrm{n}=128)$} & \multirow[b]{2}{*}{ p Value* } \\
\hline & Effective & Non-Effective & Effective/Total & Effective & Non-Effective & Effective/Total & \\
\hline Pain disorder & 19 & 11 & $63.3 \%$ & 87 & 21 & $80.6 \%$ & 0.048 \\
\hline Lumbar function & 14 & 16 & $46.7 \%$ & 61 & 44 & $58.1 \%$ & 0.267 \\
\hline Walking ability & 21 & 11 & $65.6 \%$ & 99 & 25 & $79.8 \%$ & 0.089 \\
\hline Social life & 7 & 24 & $22.6 \%$ & 79 & 48 & $62.2 \%$ & $<0.001$ \\
\hline Psychological disorder & 8 & 24 & $25.0 \%$ & 49 & 78 & $38.6 \%$ & 0.152 \\
\hline
\end{tabular}

Boldface type indicates statistical significance.

${ }^{*}$ Chi-square test.

557 non-KOA patients according to only medical history. Although there was a significant difference in age between the two groups (Supplementary Table 2), the additional analysis revealed that the frequency of "effective" was markedly lower in the KOA group than in the control group, especially in the domains of pain disorder, walking ability, and social life on the JOABPEQ (Supplementary Table 3).

\section{Discussion}

The present study showed that all HRQOL parameters of LSS patients with KOA were markedly improved postoperatively, suggesting that lumbar spinal surgery offered adequate symptom relief to these patients. However, compared with LSS patients without KOA, those with KOA experienced difficulty in routine work or ordinary activities even after lumbar spinal surgery.

Consistent with our results, Ho et al. reported that the presence of preoperative KOA was a poor prognostic factor for 1-year surgical outcomes of LSS. ${ }^{11}$ However, because the past study used a single HRQOL parameter, the details of poor prognosis have remained unclear. In the present study, multiple HRQOL analysis revealed that the postoperative outcomes of the VAS for buttocks and lower limbs and SF-36 domains of physical functioning, role physical, and vitality were significantly worse in LSS patients with KOA than in LSS patients without KOA. In addition, LSS patients with KOA manifested significantly lower pain disorder and social life functions, as assessed by the JOABPEQ, than those without KOA. These results suggest that the KOA condition may exert an adverse effect on the surgical outcome of lumbar spinal surgery in LSS patients. The residual knee pain in LSS patients with KOA may be explained by a significant difference in postoperative VAS scores for buttocks and lower limbs. Additionally, a low score for physical functioning on the SF-36 indicates the limited ability of LSS patients with KOA to climb up and down stairs and walk on flat land. The role physical domain on the SF-36 and social life domain on the JOABPEQ include common contents of work or activities in the questions. The actual questions of the role physical domain on the SF-36 are "Cut down the amount of time you spent on work or other activities?" and "Were limited in the kind of work or other activities?"5; furthermore, those of the social life domain on the JOABPEQ are "Have you been unable to do your work or ordinary activities as well as you would like?" and "Has your work routine been hindered because of the pain?" We believe that the consistency of low scores for these two different HRQOL parameters in LSS patients with KOA strongly suggests that these patients experience difficulty in routine work or ordinary activities due to knee pain or restricted knee ROM, even after lumbar spinal surgery. Hence, when obtaining the consent for lumbar spinal surgery, LSS patients with KOA should be informed that the surgical outcome is favorable but poorer than that for those without $\mathrm{KOA}$, particularly in terms of walking on steps and flat land, and with social activities, including routine work and ordinary activities.

To date, several studies have reported the correlation between hip osteoarthritis and spinal degenerative disease. ${ }^{4,12,14}$ To elucidate the precise impact of KOA on surgical outcomes of lumbar spinal surgery for LSS patients, 19 patients with hip osteoarthritis (which is arthritis of the lower extremity, as with KOA) were excluded from our investigation. Interestingly, of the 19 cases with hip osteoarthritis, 11 (57.9\%) were complicated by KOA. Previous studies have already demonstrated the occurrence of osteoarthritis at multiple sites in an individual. ${ }^{1,10,18}$ In the present study, both lumbar intervertebral disc degeneration and facet joint osteoarthritis were significantly more progressive in LSS patients with KOA than in those without KOA. These observations suggest that patients with single-site osteoarthritis should be judiciously monitored for the development of systemic musculoskeletal degeneration.

This study has several limitations. First, our data were retrospectively collected from a limited number of patients. Second, the follow-up period in this study was comparatively short. Third, our patients with KOA were diagnosed by referring to their medical history and validated based on knee radiographs. Thus, a selection bias existed in this study because we did not examine the knee radiographs of patients without KOA. Furthermore, because we did not investigate physical findings of the knee joint, knee-specific HRQOL parameters, and diagnostic knee injections, we could not determine that the postoperative residual symptoms of LSS patients with KOA were derived from the knee joint. Nevertheless, this study demonstrated that KOA attenuated the efficacy of lumbar spinal surgery in LSS patients, as assessed based on multiple HRQOL parameters. 


\section{Conclusions}

LSS patients with KOA exhibited a markedly improved surgical outcome at 1-year follow-up. However, they manifested poorer postoperative outcome, particularly in terms of social life and activities, than did patients without KOA. These results indicate that preoperative KOA status should be considered when planning treatment for LSS patients and estimating the efficacy of lumbar spinal surgery.

\section{Acknowledgments}

We would like to thank Tsugikazu Kataoka, Hironobu Watanabe, Kiyohiro Nakamichi, and Atsuko Tachibana for providing data. We are grateful to Keisuke Kato, Ryo Kobayashi, and Saki Koda for data collection.

\section{References}

1. Cerhan JR, Wallace RB, el-Khoury GY, Moore TE: Risk factors for progression to new sites of radiographically defined osteoarthritis in women. J Rheumatol 23:1565-1578, 1996

2. Cheung KM, Karppinen J, Chan D, Ho DW, Song YQ, Sham $P$, et al: Prevalence and pattern of lumbar magnetic resonance imaging changes in a population study of one thousand fortythree individuals. Spine (Phila Pa 1976) 34:934-940, 2009

3. Davis MA, Ettinger WH, Neuhaus JM, Mallon KP: Knee osteoarthritis and physical functioning: evidence from the NHANES I Epidemiologic Followup Study. J Rheumatol 18:591-598, 1991

4. Fogel GR, Esses SI: Hip spine syndrome: management of coexisting radiculopathy and arthritis of the lower extremity. Spine J 3:238-241, 2003

5. Fukuhara S, Suzukamo Y: Manual of SF-36v2, Japanese version. Kyoto: Institute for Health Outcomes \& Process Evaluation Research, 2004

6. Fukui M, Chiba K, Kawakami M, Kikuchi S, Konno S, Miyamoto M, et al: Japanese Orthopaedic Association Back Pain Evaluation Questionnaire: initial report. J Orthop Sci 12:443-450, 2007

7. Fukui M, Chiba K, Kawakami M, Kikuchi S, Konno S, Miyamoto M, et al: Japanese Orthopaedic Association Back Pain Evaluation Questionnaire. Part 2. Verification of its reliability. J Orthop Sci 12:526-532, 2007

8. Fukui M, Chiba K, Kawakami M, Kikuchi S, Konno S, Miyamoto M, et al: Japanese Orthopaedic Association Back Pain Evaluation Questionnaire. Part 3. Validity study and establishment of the measurement scale. J Orthop Sci 13:173-179, 2008

9. Fukui M, Chiba K, Kawakami M, Kikuchi S, Konno S, Miyamoto M, et al: JOA Back Pain Evaluation Questionnaire (JOABPEQ)/JOA Cervical Myelopathy Evaluation Questionnaire (JOACMEQ). The report on the development of revised versions. J Orthop Sci 14:348-365, 2009

10. Hassett G, Hart DJ, Doyle DV, March L, Spector TD: The relation between progressive osteoarthritis of the knee and long term progression of osteoarthritis of the hand, hip, and lumbar spine. Ann Rheum Dis 65:623-628, 2006

11. Ho Lee B, Kim TH, Chong HS, Lee SH, Park JO, Kim HS, et al: Prognostic factors for surgical outcomes including preoperative total knee replacement and knee osteoarthritis status in female patients with lumbar spinal stenosis. J Spinal Disord Tech 28:47-52, 2015
12. Matsuyama Y, Hasegawa Y, Yoshihara H, Tsuji T, Sakai Y, Nakamura H, et al: Hip-spine syndrome: total sagittal alignment of the spine and clinical symptoms in patients with bilateral congenital hip dislocation. Spine (Phila Pa 1976) 29:2432-2437, 2004

13. McNamara MJ, Barrett KG, Christie MJ, Spengler DM: Lumbar spinal stenosis and lower extremity arthroplasty. J Arthroplasty 8:273-277, 1993

14. Offierski CM, MacNab I: Hip-spine syndrome. Spine (Phila Pa 1976) 8:316-321, 1983

15. Pathria M, Sartoris DJ, Resnick D: Osteoarthritis of the facet joints: accuracy of oblique radiographic assessment. Radiology 164:227-230, 1987

16. Rampersaud YR, Ravi B, Lewis SJ, Stas V, Barron R, Davey $\mathrm{R}$, et al: Assessment of health-related quality of life after surgical treatment of focal symptomatic spinal stenosis compared with osteoarthritis of the hip or knee. Spine J 8:296304, 2008

17. Schneiderman G, Flannigan B, Kingston S, Thomas J, Dillin WH, Watkins RG: Magnetic resonance imaging in the diagnosis of disc degeneration: correlation with discography. Spine (Phila Pa 1976) 12:276-281, 1987

18. Shakoor N, Block JA, Shott S, Case JP: Nonrandom evolution of end-stage osteoarthritis of the lower limbs. Arthritis Rheum 46:3185-3189, 2002

19. Turner JA, Ersek M, Herron L, Deyo R: Surgery for lumbar spinal stenosis. Attempted meta-analysis of the literature. Spine (Phila Pa 1976) 17:1-8, 1992

20. Williams MG, Wafai AM, Podmore MD: Functional outcomes of laminectomy and laminotomy for the surgical management lumbar spine stenosis. J Spine Surg 3:580-586, 2017

21. Yagi M, Kaneko S, Yato Y, Asazuma T: Standing balance and compensatory mechanisms in patients with adult deformity. Spine (Phila Pa 1976) 42:E584-E591, 2017

\section{Disclosures}

The authors report no conflict of interest concerning the materials or methods used in this study or the findings specified in this paper.

\section{Author Contributions}

Conception and design: Fujita. Acquisition of data: Ozaki, Miyamoto, Kono. Analysis and interpretation of data: Fujita, Ozaki, Miyamoto. Drafting the article: Fujita, Ozaki. Critically revising the article: Fujita, Ozaki. Reviewed submitted version of manuscript: all authors. Approved the final version of the manuscript on behalf of all authors: Fujita. Statistical analysis: Miyamoto. Administrative/technical/material support: Fujita, Ozaki, Miyamoto, Kono. Study supervision: Watanabe.

\section{Supplemental Information \\ Online-Only Content}

Supplemental material is available with the online version of the article.

Supplementary Tables 1-3. https://thejns.org/doi/suppl/ 10.3171/2019.10.SPINE19886.

\section{Correspondence}

Nobuyuki Fujita: Keio University School of Medicine, Tokyo, Japan.nfujita@a7.keio.jp. 